\title{
Experiment of Gold and Silver Extraction from Cyanide Tailings by Melting Chlorination
}

\author{
Sun Yanwen, Yuan Chaoxin, Guo Chihao, Li Dajiang, Li Yibin, Mu Liangzhao \\ BGRIMM Technology Group, Beijing, China \\ Email address: \\ maccosun@126.com (Sun Yanwen)
}

To cite this article:

Sun Yanwen, Yuan Chaoxin, Guo Chihao, Li Dajiang, Li Yibin, Mu Liangzhao. Experiment of Gold and Silver Extraction from Cyanide Tailings by Melting Chlorination. International Journal of Mineral Processing and Extractive Metallurgy. Vol. 6, No. 2, 2021 , pp. $20-23$. doi: 10.11648/j.ijmpem.20210602.11

Received: April 21, 2021; Accepted: May 6, 2021; Published: May 14, 2021

\begin{abstract}
Cyanide tailings produced in gold smelting process contain a large number of heavy metals and cyanides, which are more and more harmful to the environment. In order to reduce environmental pollution, valuable metals from cyanide tailings are recovered. The amount of calcium chloride, chlorination time, the way of adding calcium chloride and other factors on the influence of gold and silver extraction by chlorination were studied by using the raw material of cyanide tailings with melting chlorination process in this paper, and how to reduce the melting chlorination temperature was explored, and a comprehensive experiment was carried out under the best conditions. The results showed that when the chlorination temperature is $1500^{\circ} \mathrm{C}$, the chlorination time is $1 \mathrm{~h}$, and the addition amount of $\mathrm{CaCl}_{2}$ is $7 \%$, the volatilization rate of gold is $85.38 \%$, the content of gold in slag is $1.83 \mathrm{~g} / \mathrm{t}$, the volatilization rate of silver is $77.36 \%$, and the content of silver in slag is $4.12 \mathrm{~g} / \mathrm{t}$; when the chlorination temperature is $1500^{\circ} \mathrm{C}, 7 \% \mathrm{CaCl}_{2}$ is added, and the chlorination time is $15 \mathrm{~min}$, the volatilization rate of gold is $87.78 \%$, the content of gold in slag is $1.23 \mathrm{~g} / \mathrm{t}$, the volatilization rate of silver is $59.40 \%$, and the content of silver in slag is $7.39 \mathrm{~g} / \mathrm{t}$; the addition of $5 \% \mathrm{CaO}$ can change the slag type, reduce the chlorination temperature by $50 \sim 100^{\circ} \mathrm{C}$, increase the volatilization rate of gold and silver slightly, and decrease the content of gold and silver in slag; when $\mathrm{CaCl}_{2}$ is added in five times, the volatilization rate of gold increases to $95.53 \%$, the content of gold in slag decreases to $0.56 \mathrm{~g} / \mathrm{t}$, the volatilization rate of silver increases to $77.80 \%$, and the content of silver in slag decreases to $4.04 \mathrm{~g} / \mathrm{t} ; 7 \% \mathrm{CaCl}_{2}$ was added in five times, and the melting chlorination time was $15 \mathrm{~min}$. the amount of $\mathrm{CaO}$ was $5 \%$, and the melting chlorination temperature was $1450^{\circ} \mathrm{C}$, the gold volatilization rate is $95.69 \%$, and the gold content of slag is $0.54 \mathrm{~g} / \mathrm{t}$, the silver volatilization rate is $77.06 \%$ and the silver content of slag is $4.20 \mathrm{~g} / \mathrm{t}$.
\end{abstract}

Keywords: Cyanide Tailings, Melting Chlorination, Calcium Chloride, Calcium Oxide, Volatile Rate

\section{Introduction}

Cyanide tailings are a kind of waste residue of gold cyanidation smelting, which contains a large number of heavy metals [1] and cyanide. The accumulation of cyanide tailings is more and more harmful to environment. Now it is necessary to develop a gold extraction technology which can efficiently recover valuable metals from cyanide tailings, reduce environmental pollution and realize integrated recycling of resources. There are many researches [2-5] on how to recover gold from cyanide tailings. In recent years, chloridizing roasting process has been mainly used to treat cyanide tailings [6-15]. On the basis of photosynthetic method, BGRIMM Technology Group (hereinafter referred to as "BGRIMM") has developed chlorination roasting volatilization process to recover valuable elements such as gold and silver from cyanide tailings. The process has been successfully applied in many smelters in china, with the abilities to efficiently recover gold and integrally recover other valuable elements. Chloridizing roasting process is suitable for tailings containing high percentage gold and silver, and it needs to consume a lot of energy. Now BGRIMM has further developed a new generation of chlorination volatilization process for gold extraction based on the existing chlorination roasting process. It is a process for integrated recycling of gold, silver and other valuable metals from cyanide tailings by short process molten salt chlorination under high temperature. The process has the characteristics of high volatile rate, high metal 
recovery rate, small amount of flue gas and without secondary hazardous waste tailings. It can effectively deal with cyanide tailings and realize gold extraction without cyanide.

\section{Experiment}

\subsection{Experiment Material}

The raw material is cyanide tailings (hereinafter referred to as "tailings") with fine particle size (- $0.074 \mathrm{~mm}>95 \%)$ provided by a company, and the main ingredients are shown in Table 1. Due to the high content of gold and silver, the raw material has high recovery value. The tailings were used for experiment after drying, mixing and dividing. The iron in the raw material mainly exists in trivalent form, and the contents of copper, lead and zinc are not high, so this paper focuses on the volatile extraction of gold and silver from tailings.

Table 1. Chemical composition of cyanide tailings.

\begin{tabular}{|c|c|c|c|c|c|c|c|c|c|c|c|c|c|c|}
\hline composition & $\mathrm{Au}^{1)}$ & $\mathbf{A g}^{1)}$ & $\mathrm{Cu}$ & $\mathbf{P b}$ & $\mathrm{Zn}$ & $\mathrm{TFe}$ & $\mathrm{Fe}^{2+}$ & $\mathrm{CaO}$ & MgO & $\mathrm{Al}_{2} \mathrm{O}_{3}$ & $\mathrm{SiO}_{2}$ & As & $\mathbf{S}$ & $\mathrm{C}$ \\
\hline Content (\%) & 12.52 & 18.2 & 0.23 & 0.26 & 0.36 & 31.38 & 0.70 & 1.75 & 0.75 & 15.75 & 30.15 & 1.39 & 1.14 & 0.41 \\
\hline
\end{tabular}

Note: 1) unit is $\mathrm{g} / \mathrm{t}$

\subsection{Experiment}

Combined phase diagram corresponding to the tailings' composition and the gray cone method, the melting point of the tailings used in the experiment was $1434^{\circ} \mathrm{C}$. Firstly, crucible with $100 \mathrm{~g}$ tailings was put into muffle furnace. Raised the muffle furnace temperature to $1500^{\circ} \mathrm{C}$ and kept the temperature for $0.5 \mathrm{~h}$ to make the tailings in molten state. Then, calcium chloride was added to the molten tailings, put them into muffle furnace for molten chlorination experiment after full stirring. Finally, the gold and silver contents in the tailings were analyzed after chlorinated, air-cooled, vibrational milled and sampled.

\section{Results and Discussion}

\subsection{Effect of $\mathrm{CaCl}_{2}$ Addition Amount on Gold Extraction}

When the melting chlorination temperature of cyanidation tailings was $1500^{\circ} \mathrm{C}$ and the chlorination time was $1.0 \mathrm{~h}$, the effect of $\mathrm{CaCl}_{2}$ addition amount on the volatile rate of gold and silver in the tailings is shown in Figure 1.

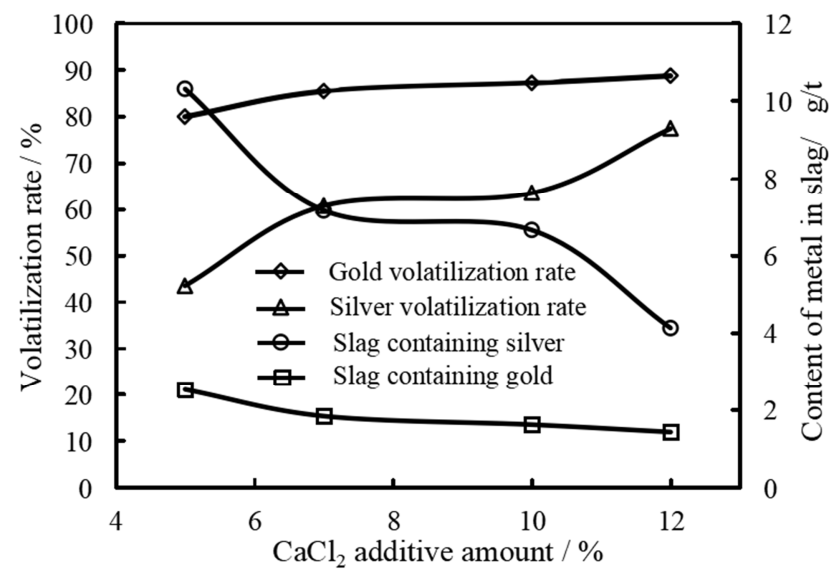

Figure 1. The effect of $\mathrm{CaCl}_{2}$ addition amount on gold and silver volatile rate.

Figure 1 shows that the addition amount of calcium chloride has a significant effect on the volatile rate of gold and silver. When the addition of $\mathrm{CaCl}_{2}$ increased from $5 \%$ to $7 \%$, the volatile rate of gold increased from $79.87 \%$ to $85.38 \%$, and the gold content in tailing was $1.83 \mathrm{~g} / \mathrm{t}$. After that, the gold volatile rate increased a little with the increase of $\mathrm{CaCl}_{2}$. The volatile rate of gold only increased by $3 \%$ when the addition of calcium chloride increased by $5 \%$, and the gold content in tailing only decreased by $0.4 \mathrm{~g} / \mathrm{t}$ to $1.42 \mathrm{~g} / \mathrm{t}$. The results show that the $7 \%$ addition of $\mathrm{CaCl}_{2}$ can meet the experiment conditions. The silver volatile rate increased significantly with the increase of calcium chloride addition. When the addition amount of $\mathrm{CaCl}_{2}$ increased from $5 \%$ to $12 \%$, the silver volatile rate increased from $43.41 \%$ to $77.36 \%$, and the silver content in tailing was $4.12 \mathrm{~g} / \mathrm{t}$ with good effect.

\subsection{Effect of Chlorination Time on Gold Extraction}

Experiment conditions: the melting chlorination temperature of tailings was $1500^{\circ} \mathrm{C}$, the addition of $\mathrm{CaCl}_{2}$ was $7 \%$ in the molten state, and the stir was thorough. On this condition, the effect of chlorination time on the volatile rate of gold and silver in tailings is shown in Figure 2.

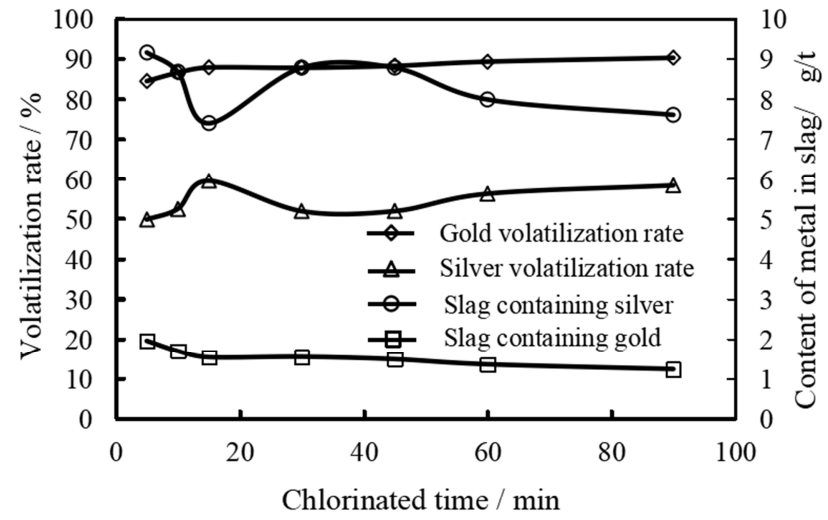

Figure 2. The effect of chlorination time on gold and silver volatile rate.

The results show that the gold volatile rate increased markedly firstly and then increased gently with the increase of chlorination time. The gold volatile rate increased by $3.36 \%$ from $5 \mathrm{~min}$ to $15 \mathrm{~min}$. The volatile rate was $87.78 \%$ at $15 \mathrm{~min}$ and $90.18 \%$ at $90 \mathrm{~min}$. At $15 \mathrm{~min}$, the gold content in the tailing was high, which was $1.23 \mathrm{~g} / \mathrm{t}$. Keep increasing the melting chlorination time has little effect on reducing the gold content in tailing. The silver volatilization increased when chlorination time was in the range of $5 \mathrm{~min}$ to $15 \mathrm{~min}$, the 
maximum volatile rate was $59.40 \%$ and the silver content in tailing was $7.39 \mathrm{~g} / \mathrm{t}$. The volatile rate of silver fluctuated slightly after $15 \mathrm{~min}$, ranging from $51.81 \%$ to $59.40 \%$. Above analysis indicates the best melting chlorination time is $15 \mathrm{~min}$.

\subsection{Research on Reducing Melting Temperature}

The complete melting temperature of cyanide tailings is $1500{ }^{\circ} \mathrm{C}$ under the laboratory conditions. The temperature and energy consumption are both high. The melting point will reduce by changing the tailing composition. The main compositions of cyanide tailings are iron, silicon, calcium and aluminum. Divalent iron only accounts for $0.7 \%$ of the total iron, the iron mainly exists in the form of trivalent iron. The percentage of alumina is up to $15.72 \%$, meanwhile, the percentage of $\mathrm{CaO}$ is only $1.75 \%$. These factors lead to high melting temperature. Based on the phase diagram of $\mathrm{Fe}-\mathrm{Si}-\mathrm{Ca}-\mathrm{Al}$, it is decided to reduce the melting point by adding $\mathrm{CaO}$.

Experiment conditions: first of all, one sample added 5\% $\mathrm{CaO}$ and the other did not. $7 \% \mathrm{CaCl}_{2}$ was added to samples in the molten state and stirred thoroughly. Then, put them into muffle furnace quickly for melting chlorination for $15 \mathrm{~min}$. Lastly, the gold and silver contents in the tailings were analyzed after chlorinated, air-cooled, vibrational milled and sampled. The experiment phenomenon is shown in Figure 3, and the results are shown in Table 2.

Table 2. Effects of adding $\mathrm{CaO}$ on the volatile rate of gold and silver.

\begin{tabular}{|c|c|c|c|c|}
\hline Experiment condition & gold content in the tailing $(\mathrm{g} / \mathrm{t})$ & gold volatile rate $(\%)$ & silver content in the tailing $(\mathrm{g} / \mathrm{t})$ & silver volatile rate $(\%)$ \\
\hline With $\mathrm{CaO}$ & 1.34 & 89.30 & 73.08 & 4.9 \\
\hline Without $\mathrm{CaO}$ & 1.52 & 87.86 & 64.84 & 6.4 \\
\hline
\end{tabular}

Figure 3 is the cooling diagram of cyanide tailings cinder, in which (a) is without $\mathrm{CaO}$ and (b) is added $\mathrm{CaO}$. The results show that the addition of $\mathrm{CaO}$ can reduce the melting temperature by $50^{\circ} \mathrm{C} \sim 100{ }^{\circ} \mathrm{C}$. It can be seen from the experiment phenomenon that the fluidity of adding $\mathrm{CaO}$ is better than without $\mathrm{CaO}$. The effect of $\mathrm{CaO}$ addition on the volatile rate of gold and silver is shown in Table 2 .

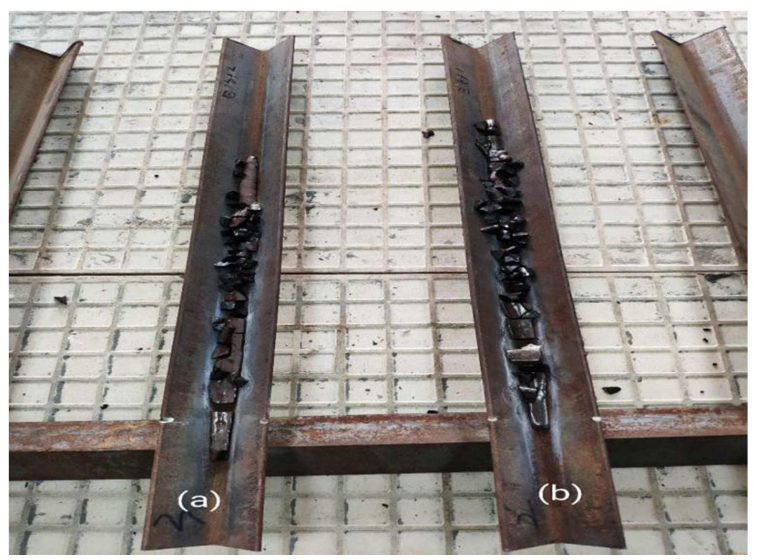

Figure 3. Schematic diagram of cinder fluidity.

Table 2 shows that the addition of $\mathrm{CaO}$ can reduce the contents of gold and silver in the tailing. The addition of $\mathrm{CaO}$ increased the tailing mass by 1.05 times, however, the gold content in tailing was still lower than that without $\mathrm{CaO}$. The volatile rate of gold was slightly increased by $1.44 \%$, but the silver volatile rate increased by $8.24 \%$. In addition, the addition of $\mathrm{CaO}$ can reduce the melting point and improve the fluidity of the molten melt at $1450{ }^{\circ} \mathrm{C}$, which is beneficial for the melting chlorination experiment.

\subsection{Effect of Adding $\mathrm{CaCl}_{2}$ in Batches on Gold Extraction}

Experiment conditions: the cyanide tailings were melted at $1450{ }^{\circ} \mathrm{C}$ after adding $5 \% \mathrm{CaO}$. In the molten state, $7 \% \mathrm{CaCl}_{2}$ was added in batches and stirred fully with 15 min intervals. The effect of adding calcium chloride in batches on gold and silver volatile rate are presented in Figure 4.

It can be found from Figure 4 that the volatile rate of gold increased by $10.03 \%$ from $85.50 \%$ to $95.53 \%$ when the adding times of $\mathrm{CaCl}_{2}$ increased from one time to five times. And the gold content in tailing was reduced from $1.69 \mathrm{~g} / \mathrm{t}$ to $0.56 \mathrm{~g} / \mathrm{t}$, which realized the experiment purpose. The silver volatile rate also increased by $5.77 \%$, from $72.03 \%$ to $77.80 \%$. The silver content in tailing decreased to $4.04 \mathrm{~g} / \mathrm{t}$, and the volatilization effect was good. These illustrate that adding calcium chloride in batches has great effect on the volatile rate of gold and silver.

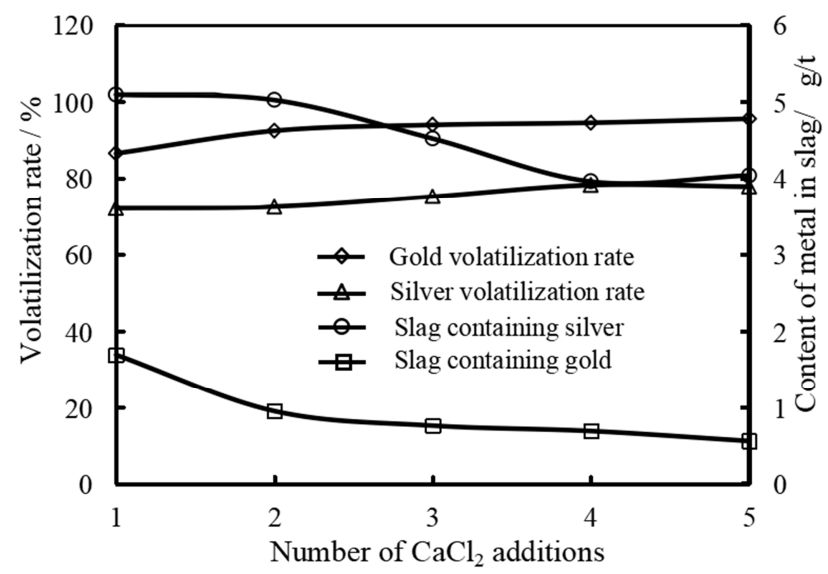

Figure 4. The effect of adding calcium chloride in batches on gold and silver volatile rate.

\subsection{Comprehensive-factor Experiment}

According to $2.1 \sim 2.4$, the best experiment conditions were as follows: $100 \mathrm{~g}$ cyanide tailings was weighed, the addition amount of $\mathrm{CaO}$ was $5 \%$, the melting chlorination temperature was $1450^{\circ} \mathrm{C}$. And the addition amount of $\mathrm{CaCl}_{2}$ was $7 \%$, which was added in five times with 15 minutes interval. The mixture was also thorough. Chlorination was performed for 15 minutes, followed by air-cooled and vibrational milled, sampled for analysis was the last step. The results are shown in Table 3. 
Table 3. Contents and volatile rates of gold and silver in tailing under comprehensive-factor experiment.

\begin{tabular}{lllll}
\hline \multirow{2}{*}{ Number of experiments } & Composition of tailing, $(\mathbf{g} / \mathbf{t})$ & \multicolumn{2}{c}{ volatile rate, $(\%)$} \\
\cline { 2 - 6 } & $\mathbf{A u}$ & $\mathbf{A g}$ & $\mathbf{A u}$ & $\mathbf{A g}$ \\
\hline 1 & 0.56 & 4.04 & 95.53 & 78.02 \\
2 & 0.52 & 4.35 & 95.85 & 76.10 \\
mean value & 0.54 & 4.20 & 95.69 & 77.06 \\
\hline
\end{tabular}

The comprehensive-factor experiments show that the gold volatile rate was $95.69 \%$, the content of gold in tailing was $0.54 \mathrm{~g} / \mathrm{t}$, and the volatile rate of silver was $77.06 \%$, the silver content of silver in tailing was $4.20 \mathrm{~g} / \mathrm{t}$. The experiments achieved the expected goal.

\section{Conclusion}

The volatilization of gold and silver in cyanide tailings was studied by melting chlorination in this work.

(1) When the chlorination temperature is $1500^{\circ} \mathrm{C}$, the chlorination time is $1 \mathrm{~h}$, and the addition amount of $\mathrm{CaCl}_{2}$ is $7 \%$, the volatilization rate of gold is $85.38 \%$, the content of gold in slag is $1.83 \mathrm{~g} / \mathrm{t}$, the volatilization rate of silver is $77.36 \%$, and the content of silver in slag is 4.12 $\mathrm{g} / \mathrm{t}$;

(2) When the chlorination temperature is $1500^{\circ} \mathrm{C}, 7 \% \mathrm{CaCl}_{2}$ is added, and the chlorination time is $15 \mathrm{~min}$, the volatilization rate of gold is $87.78 \%$, the content of gold in slag is $1.23 \mathrm{~g} / \mathrm{t}$, the volatilization rate of silver is $59.40 \%$, and the content of silver in slag is $7.39 \mathrm{~g} / \mathrm{t}$;

(3) The addition of $5 \% \mathrm{CaO}$ can change the slag type, reduce the chlorination temperature by $50 \sim 100^{\circ} \mathrm{C}$, increase the volatilization rate of gold and silver slightly, and decrease the content of gold and silver in slag; when $\mathrm{CaCl}_{2}$ is added in five times, the volatilization rate of gold increases to $95.53 \%$, the content of gold in slag decreases to $0.56 \mathrm{~g} / \mathrm{t}$, the volatilization rate of silver increases to $77.80 \%$, and the content of silver in slag decreases to 4.04 $\mathrm{g} / \mathrm{t}$;

(4) $7 \% \mathrm{CaCl}_{2}$ was added in five times, and the melting chlorination time was $15 \mathrm{~min}$. the amount of $\mathrm{CaO}$ was $5 \%$, and the melting chlorination temperature was $1450{ }^{\circ} \mathrm{C}$, the gold volatilization rate is $95.69 \%$, and the gold content of slag is $0.54 \mathrm{~g} / \mathrm{t}$, the silver volatilization rate is $77.06 \%$ and the silver content of slag is $4.20 \mathrm{~g} / \mathrm{t}$.

\section{References}

[1] Lv Cuicui, Ding Jian, Fu Guoyan, et al. Current situation and prospect of recovery of valuable elements from cyanide tailings [J]. CIESC Journal, 2016, 67 (4): 1079-1089.

[2] Sun Liugen, Chang Yaochao, Xu Xiaohui, et al. Current status and development trend of main technologies for harmless and resource utilization of cyanide tailings $[\mathrm{J}]$. China Comprehensive Utilization of Resources, 2017, 35 (10): 59-62.
[3] GHOBEITIHASAB M, RASHCHI F, RAYGAN S. Chloride hypochlorite leaching and hydrochloric acid washing in multi-stages for extraction of gold from a refractory concentrate [J]. Hydrometallurgy, 2014, 142 (2): 56-59.

[4] LYU C C, DING J, QIAN P, et al. Comprehensive recovery of metals from cyanidation tailing [J]. Minerals Engineering, 2015, 70: 141-147.

[5] Wang Weida, Feng Yali, Li Haoran, et al. Recovery of gold from cyanide tailings by alkaline leaching desilication process [J]. The Chinese Journal of Nonferrous Metals, 2015, 25 (1): 233-240.

[6] Sun Xudong, Pan Dean, Gong Yu, et al. Preparation of Ceramsite from Cyanide Tailings by Hi-temperature Chlorination Roasting Process $[\mathrm{J}]$. Nonferrous Metals (Smelting Section), 2020 (6): 70-79.

[7] Zhang Shuke, Qu Bangding. Experimental study on gold extraction from gold containing materials by high temperature chlorination volatilization $[\mathrm{J}]$. China Comprehensive Utilization of Resources, 2020, 38 (2): 8-10.

[8] Li Zhengyao, Wang Weiwei, Le Kun. Recovery of Gold and Iron from Cyanide Tailings by Chlorination Volatilization and Reduction Roasting with One-step Method [J]. METAL MINE, 2015, 44 (10): 173-177.

[9] Zhang Zhaohui, Jiang Hanlong, LIU Bailong, et al. Research on recovery of gold and silver from molten salt treatment of cyanide tailings by roasting $[\mathrm{J}]$. Bulletin of the Chinese Ceramic Society, 2016, 35 (2): 582-586.

[10] Liu Hongxiao, Wang Weizhen, Yang Xingqing, et al. Research on Chlorination Roasting Process of Cyanide Tailings [J]. Mining and Metallurgy, 2016, 25 (1): 75-77.

[11] Sun Liugen, Huang Haihui, Xu Xiaohui, et al. Experimental Study on Recovery of Valuable Metals from Roasting and Cyaniding Tailings [J]. Nonferrous Metals (Smelting Section), 2017 (2): 15-18.

[12] Li Dajiang, Guo Zhihao, Yuan Chaoxin, et al. Research on the process and economy of gold extraction from cyanide tailings by chlorination roasting [J]. China Comprehensive Utilization of Resources, 2018, 36 (8): 45-46.

[13] Hu Lei, Huo Songling, Guo Zhihao, et al. Experimental study on extraction of gold from chlorinated volatile gold slime [J]. Nonferrous Metals (Smelting Section), 2018 (8): 52-59.

[14] Sun Yanwen, Guo Chihao, Li Yibin. Study on chlorination of cinder from a pyrite mine in Indonesia [J]. China Comprehensive Utilization of Resources, 2020, 38 (8): 1-4.

[15] Liang Dongdong, Guo Zhihao, Yuan Chaoxin, et al. Experimental study on gold extraction from gold bearing materials by chlorination [J]. Nonferrous Metals (Metallurgical Section), 2019 (10): 63-66. 